\title{
Anxious Context of the Health Crisis and Subjective Lived Experience of People with COVID-19 in Cameroon: A Phenomenological Interpretative Analysis
}

\author{
Tchokote Emilie Clarisse ${ }^{1 *}$, Nguimfack Leonard ${ }^{2}$ and Mgbwa \\ Vandelin $^{3}$ \\ ${ }^{1}$ Department of Sciences of Education. University of Yaoundé I, Cameroon \\ ${ }^{2}$ Department of Psychology, University of Yaoundé I, Cameroon \\ ${ }^{3}$ Department of Sciences of Education, University of Yaoundé I, Cameroon \\ *Corresponding Author: Tchokote Emilie Clarisse, Lecturer, Department of Sciences \\ of Education. University of Yaoundé I, Cameroon.
}

Received: April 29, 2020

Published: May 21, 2020

(C) All rights are reserved by Tchokote

Emilie Clarisse., et al.

\section{Abstract}

Faced with the current context marked by the sudden appearance of the Coronavirus pandemic (nCoV2) in the world in general and in Cameroon in particular, the need for a readjustment in lifestyle has been imposed on people. The health crisis has forced governments around the world to take measures to readjust people's behavior, in order to allow them to escape the risk of collapse on all aspects.

The article aims to understand the meaning that people give to their subjective lived experience in such an anxious context marked by the health crisis due to the corona virus.

Through the qualitative clinical method, the comprehensive approach and the phenomenological interpretative analysis, nine interviews were conducted with the nine participants residing in the city of Yaoundé in Cameroon and exercising in different professions. The results show that the participants live an experience marked by a strong felt anxiety, painful emotions, fear, anger, a feeling of weakness and insecurity and stress. Faced with these painful experiences, the participants implemented a set of cognitive and behavioral efforts which need to be reinforced by psychological care.

Keywords: Anxiety; Subjective Lived Experience; Coronavirus; Phenomenological Interpretative Analysis; Health Crisis; Psychological Weakening

\section{Introduction}

The world has been facing a planetary threat since 31rst December 2019 due to a pandemic of Coronavirus Disease (COVID19) that first started in China [1]. The Coronavirus Disease is a disease that is caused by Severe Acute Respiratory Syndrome (SRAS) and is currently in its second strain (nCov2). According to research [1], the transmission of the virus to humans took place through the manipulation of the animal, in this case the pangolin whose strain would be the bat. Although the source of the transmission of coronavirus to human is still an hypothesis, the fact remains that the path of animal's origin is most likely.

According to World Health Organization (WHO) [2], the SRAS is the first serious and highly transmissible disease that emerged in the $20^{\text {th }}$ century. It is known as a new, enigmatic and disturbing disease.
The corona virus belongs to a family known for its multiple mutations, which obliges to consider it as an extremely serious threat, especially since there is currently no vaccine or treatment that is known to be efficient and reliable. It is in this logic that, the tools for controlling empirical microbiology, namely quarantine and isolation for people already infected, are highly recommended, the barrier measures to limit the spread of the virus such as frequent hand washing in an appropriate manner (with running water and soap), the use of hydro-alcoholic gel to disinfect the hands regularly, sneezing technics to avoid spread of the virus in the air (in the hollow of the elbow), the use of the single handkerchief and face masks as well as the avoidance of certain behaviours in situations of interrelation and communication (avoid kissing, shaking hands, manipulating the nose and mouth and respecting a social distance of at least one meter in a face-to-face situation, etc.)

The dangerousness of the virus and the damage up till now created in the world in general, report many people infected and 
many cases of death. As of April 27,2020, there were already about 2,995,043 confirmed cases and 207,000 deaths worldwide. The mortality rate is constantly increasing [3]. In Cameroon in particular, statistics show 1621 confirmed cases and 56 cases of death [4]. The occurrence of the coronavirus pandemic (nCoV) is an issue that concerns the collaboration of all health stakeholders. These actors must therefore monitor the evolution of the pandemic, seek to understand its dynamics and anticipate its impact on the population.

It is in this context of preserving the general population face of this health threat that, most countries have adopted measures ranging from closing the borders to strong recommendations such as: the quarantine of infected people, isolation, compliance with the barrier measures and confinement. Confinement is a measure that aims to limit the spread of the virus field. It aims to reduce human contact and avoid contamination. However, several studies have demonstrated the dangerousness of confinement on the lives of the people concerned, with significant psychological repercussions [5-9].

The action of involuntarily confine, marks a certain deprivation in the fundamental freedoms of man and a confinement which is experienced firstly physically and then psychically. The research on the degree of psychological distress faced with confinement in the Chinese population through a self-questionnaire [5] reveals a high frequency of anxiety, depression, avoidance behaviour and various symptoms on individuals.

According to this survey, women have a higher degree of psychological distress than men; and this distress is more increased among migrant workers and young people aged 18 to 20 compared to people over the age of 60 .

According to this study, it would therefore be a question of taking into account the specific needs of vulnerable groups such as young people, the elderly and migrant workers. In addition, it is strongly recommended to set up support and accompaniment services aimed at targeted interventions to reduce psychological stress.

Another study concerning the psychological impact of confinement [10] was written as a summary note from 3166 articles. This study shows that, the confinement in the case of the appearance in 10 countries of the SARS virus, of Ebola and the H1N1 virus, as well as the duration of the confinement, are stressors. Post-traumatic symptoms, avoidance behaviours and anger can appear for more than 10 days. The stressors related to the effect of confinement can come from: fear of infection and worry about illness, boredom and frustration, the feeling of isolation caused by the situation of confinement and the difficulty to get in relation with others, the social distance to observe, all kinds of confusion linked in particular to the inadequacy of information and the lack of understanding of the purpose of confinement, the difficulties of appropriating the property of first necessity etc.

Also, the end of confinement does not mark the end of stress on the individual, because the economic consequences linked to the slowdown in socio-economic activities $[11,12]$ are to be considered and can generate anger and anxiety. We can also observe a high degree of vulnerability in the independents workers [13], precariousness can be accentuated in people already economically weaken and unable to continue their profession by remote work, the stigmatization of people representing or having represented a danger of spread of the disease.

In Cameroon, certain measures have been adopted and are constantly encouraged by the administrative and health authorities $[14,15]$. These include the closing of land, air and sea borders; the closure of all public and private nursery, primary, secondary and university training institutions, as well as vocational training center. In fact, these are restrictive measures prescribed by the Cameroonian state [14] dated $17^{\text {th }}$ March 2020. It is clear to note with the Prime Minister of Cameroon [15] in a special declaration of March 24, 2020, that these restrictive measures aimed at limiting the spread of the corona virus, are not respected by a very large number of Cameroonians.

This declaration reiterates the systematic closure of drinking places, restaurants and places of leisure from 6 p.m.; the prohibition on gatherings of more than 50 people, the prohibition of overloads in buses, taxis and bike riders, restricting urban and interurban travel, regulating the flow of consumers in markets and shopping centers, respect for hygienic rules and social distancing measures prescribed by the World Health Organization. As a result, people in Cameroon are obliged to readjust their behavior due to the occurrence of COVID-19. This implies, moreover, feelings that people can develop in such a context because it is potentially anxious.

The question is to know, how the potentially anxious context of COVID-19, is understood by the Cameroonian populations? What is their experience (subjective experience) of the measures decreed by the Cameroonian state according to the meaning they give to the pandemic and its effects?

Moreover, people in Cameroon faced with the closure of their work environment (schools, higher education, places of various professional training etc.) and finding themselves not in a situation of total confinement, but rather in a situation of "no professional occupation". Although certain measures have been recommended in order to ensure distance education, the difficulties remain as regards the observance of a kind of confinement which is not total but rather "responsible". 
Restrictive measures are taken against certain sectors of activity [14], in this case independent-employed workers (taxi-driver, bike-riders, urban and interurban means of transport, shops in markets, shopping centers, places of leisure, etc.). This new inventory of affairs obliges that, one is interested in the subjective lived experience of people facing the measures imposed by the occurrence of COVID-19.

This article seeks to analyse the subjective lived experience of people with COVID-19 in an anxious context of health crisis.

\section{Materials and Methods}

Choice and justification of research design

The present study is a phenomenological interpretative analysis [16] based on a clinical approach centered on the encounter of the concrete and singular human [17-19].

It is in fact an in-depth study of the human subject considered in its singularity, its personal history and its experience $[17,19]$. It is about highlighting the direct speech of the subjects facing COVID-19, to be able to attest to a subjective reality and to set the scene. It is in this sense that the interest granted is mainly due to the aim of the study, which is to apprehend the subjective lived experience of people in Cameroon faced with the anxious context of the COVID-19 health crisis. In other words, it is a question of analysing what they say, what they experience and what they feel in the context of the health crisis induced by the corona virus, with its lot of consequences on themselves in because of restrictions and prohibitions according to their different socio-professional status.

\section{Participants}

The participants of the study are grouped according to the different categories of people involved in the two types of measures taken by the State of Cameroon in order to limit the spread of the virus and people who are not concerned by any of the measurement categories but are affected by the coronavirus. On the one hand, It's about the participants concerned by the temporary closure of private structures (private schools and universities) and public (schools and universities) [14]. On the other hand, it's about the participants who are affected by restrictive measures in the functioning of their structure like independent employed workers (those who work on their own account) and self-employed workers subject to a labor code (those who work for example in large groups or companies) [15]. Another category of participants is concerned with people who ensure the well-being of the family on a daily basis (housewives) and people who are on retirement (elderly and/or retired).

The selection of participants was made according to the inclusion criteria of each category and subcategory identified. It's about:

- Being a kindergarten/elementary or secondary school teacher and university lecturer in the public or private sector;
- Being self-employed (on owned account) or other worker (belonging to large groups of private companies);

- Being a housewife;

- Being retired or elderly;

- Being a religious leader.

Therefore, nine participants were selected, these are three teachers (primary, secondary and university education); a selfemployed worker (taxi driver); two workers of the private sector (supermarket salesperson, private laboratory worker); three participants from other categories (a housewife, retired person, and a religious leader).

\section{Procedure}

The study took place in the city of Yaoundé, political headquarter of Cameroon, center region. The opportunity to meet the participants in their respective place of work for some and in public places for others (appointments made with teachers for example) was done in strict compliance with the barrier measures as recommended to limit the spread of the virus. For the researchers, it involved wearing a face mask, wearing gloves, respecting the social distance of one meter from the participants.

\section{Ethical considerations}

In order to respect anonymity, the pseudonyms were assigned to the participants concerned by the study. These pseudonyms are (ens1) for primary school teachers; (ens2) for secondary school teacher; (ens3) for university teacher, (cond) for taxi driver; (vend) for seller at the supermarket, (labo) for worker in a private laboratory, (mena) for housewife; (retra) for retired person, (lead1) for religious leader. Participants were informed of the purpose of the study. Informed consent forms were signed by participants, indicating their approval for the data collection.

\section{Collection tool and data analysis}

The interviews $(n=9)$ were carried out with the participants. It was question of clarifying to the participants the framework of the interview by reminding them of the objectives of the study, and the realization of the interview in the mode of an open questioning. As required in the context of a qualitative study, it was also question for the researcher to speak in a minimalist way while allowing, through his interventions, the sharing of experiences as lived by the participants and stimulating the reflexive approach among actors involved (researcher and participants) [20].

The data recorded using a dictaphone was transcribed entirely, then analyzed using the Interpretative Phenomenological Analysis (IPA) technique [16]. It is an analytical technique that allows the researcher to explore the experience of the participants, the meaning they give to their experience and the underlying psychological mechanisms. Therefore, the analysis cycle according to the IPA 
model has been followed very carefully in its implementation. After transcribing the data, a first reading of each interview sentence is done. Then, the identification and annotation of the Highlighted points make it possible to identify the main themes and subthemes relating to the content and the underlying mechanisms.

Interpretation paths are proposed in order to induce the writing of results indicating the meaning given by the participants, what the researcher understands and how he/she understands [20].

\section{Results}

The results will focus primarily on the presentation of the idiographic data of the participants. Then, the presentation of the main themes and sub-themes identified in the speeches as well as their discussion will indicate the meaning that participants give to their subjective experience linked to the anxiety-provoking context of the COVID-19 health crisis. Therefore, five main themes have been identified, these are:

- $\quad$ Lived before the occurrence of COVID-19 in Cameroon (experience related to daily activities, perception of the difficulties encountered);

- Painful experience of the announcement of the corona virus pandemic (modalities of the announcement, an experience charged with negative affects and anxiety);

- Real life experience of the threat and psychological repercussions (existence of cases of infected people and deaths due to the corona virus: from the experience of anxiety to stress, defense mechanisms and coping, fears and desires);

- Subjective lived experience of restrictive measures following covid-19 (real and subjective experiences linked to restrictive measures and the professional situation of each participant, observed behavioral change and coping strategies);

- Psychological repercussions of the imposed social distancing.

\section{Presentations of participants}

ens1 (Elementary school teacher)

The participant ens1 is a male and 28 years old teacher in a private primary school in the city of Yaoundé. Single and father of a child, he is French speaking. Originally from the center region, he is the first in a family of four children. The participant ens 1 lives with his child and his cousin.

\section{ens2 (Secondary school teacher)}

The participant ens2 is a female and 43-year-old teacher at a bilingual high school in the city of Yaoundé in Cameroon. She is married, mother of four children and English speaking. She is from the Northwest region of Cameroon and the last in a family of four. She lives with her mother and her four children. Her husband is a worker and lives in the city of Bertoua, in the East region of Cameroon.

\section{ens3 (University Lecturer)}

The participant ens3 is a male and 40 years old lecturer at a public university in Cameroon. Married and father of three, he is French speaking. Originally from the center region, he is the first in a family of six children. The participant ens3 lives with his wife and his children in the city of Yaoundé-Cameroon.

\section{cond (Taxi driver)}

The participant cond is a Male and 35 years old taxi driver. He works for his personal account in the city of Yaoundé in Cameroon. Married and father of four children, he is English speaking. Originated from the North West region, he is the second in a family of five children. The participant cond lives with his wife and four children in the city of Yaoundé.

\section{vend (Supermarket seller)}

The participant vend is a Female and 28 years old seller in a supermarket located in the city of Yaoundé. Single and mother of two children, she is French speaking. Originated from the West region of Cameroon, she is third in a family of six children. She lives with her two children and her younger sister in the city of Yaoundé.

\section{labo (Private laboratory employee)}

The participant labo is a Male and 48 years old employee in a private laboratory located in Yaoundé. Married and father of five children, he is French speaking. Originally from the West region of Cameroon. He ranks first in a family of nine children. The participant labo lives with his five children and his wife in the city of Yaoundé.

\section{mena (Unemployed housewife)}

The participant mena is 30 years old and unemployed housewife. Married and mother of three children. She is French speaking. Originated from the Center region of Cameroon. She is first in a family of four children. The participant lives with her husband and her three children.

\section{retra (Retired)}

The participant retra is a female and 63 years old retired public servant. Married and mother of six. She is a French speaking, originated from the South region of Cameroon. She is second in a family of three children. The participant retra lives with his husband and her last son.

\section{Lead1 (Religious leader)}

The participant lead1 is a male 45 years old. He is a religious leader in a religious community located in the Nkolbisson district of Yaoundé. Married and father of two children. He is French speaking. Originally from the center region, he is fourth in a family of six 
children. The participant lead1 lives with his wife and children in the city of Yaoundé.

Lived before the occurrence of COVID-19 in Cameroon: Experience related to daily activities and perception of the difficulties encountered

Before the occurrence of COVID 19, the participants declared that they had a life marked by a certain stability in terms of their daily activities, devoid of particular fears. However, we find in their speech concerns of everyday life. It is in this logic that the participant ens3 precise that "I had preoccupation related to my activities [...] there was no particular fear... I did my work as I could do it... with the capacities that I had! "We note that all the participants had an experience charged with daily difficulties and of which they had the resources to cope (retra, mena, ens1, lead1, cond).The participant ens2 stipulates that "before corona virus came, I think I was living a free life [...] like, going to sport; every morning going for a walk, going to work normally without fear. For I think I had a lot of freedom before now". the participant labo says "I led an ordinary life, I get up, I go to work, in any case I was not worried about anything, and whatever we could go through it would be quite simply a normal life, we can be sick, we can have sick children but we know that it is normal, so no particular fear!".

The participants did not hesitate in their speech to make use of coping strategies allowing them to evoke the comparison concerning the past (before the appearance of the coronavirus) and the presence (the actual experience of the situation linked to the coronavirus).

Thus, the participant mena precise that "I lived well! everything was normal, we had no problem, we weren't afraid to go out, we weren't going out with masks, so our lives were very simple, we were free to do what we wanted, go where we want, but now we are unable to go out... I am unable to go out with my child, because we do not allow children to go to the markets!".

The same feeling is spotted in the speech of the participant ens1 who states that: "As a teacher, before the sudden coming of the coronavirus at least we had plans. Things were moving on well, even though we can never work without difficulties. But at least you could have been sure of your monthly salary, sure of your job well done. We could plan on something and then be sure of executing them... but with the coming of the coronavirus, it is not certain, one is not even sure of anything, we are not sure of tomorrow! Before, you could move freely. You could plan your things and executes them! But now it is just a whole block at this point in time!".

The worry is felt by all participants, particularly regarding their ability to survive financially, the difficulty of ensuring follow-up to income-generating activities and the insecurity regarding their survival. The participant cond stipulates for this purpose that "be- fore coronavirus came, I was satisfied! But since then, my job was secured! I was not having any problem as regards to the amount that I was earning a day, a week, or during a month! Then, all activities were moving normally and my house was well placed! I was not afraid but now, I am afraid because this virus is out!".

The difficulties linked to the occurrence of COVID-19 are painfully experienced by the participants who explained how they learned about its existence in the world in general and in Cameroon in particular. The participants do not hesitate to raise economic and relational preoccupation, and human survival. In other words, they refer to the fear of death without naming it "but with the coming of the coronavirus, it is not certain, one is not even sure of anything, we are not sure of tomorrow!" (ens1).

Painful experience of the announcement of the coronavirus pandemic

For most of the participants, knowledge of the existence of the pandemic came from the media and social networks. This awareness of the real existence of the pandemic was accompanied by strong painful emotions, anxiety and strong psychological reactions. The participant ens 2 says for this purpose that: "I got it through social medias and through the television, that the coronavirus is a pandemic that is killing people seriously! I don't think anybody will feel good hearing that people are dying. Obviously, I felt bad and frightened. Yes, I felt really frightened, because we don't know who is next! [...] I got somehow confused because the announcement came and created a lot of fear and panic. Panicking because many things ran inside my mind! The fear of how I'm going to be living the life and managing my family, fear of the disease itself! Fear of me losing my job! Fear of the unknown! So, it created a lot of panic because the announcement came with the sudden suspension of gatherings, schools and so on! And as a teacher, I felt already a lot of things! How are my children going to study? A lot of panic! How am I going to survive?? A lot of panic! Will I still be able to receive my wages at the end of the month to take care of the family and pay my bills? Am I saved from this illness and is my family going to be saved? A lot of questions, a lot of worries in my mind!".

The feeling of weakness is felt by all participants, like the participant labo who says "We understand that our life is fragile and that we are also threatened (silence)!" The same feeling is related in the participant cond's speech when he specifies that: "we heard how people are dying in the whole world! It (coronavirus) brings fear! Total fear! We are afraid that, maybe we are the next victim. When I realize that this issue of coronavirus is in my country, I feel sad! Very sad! Discourage! And worried because of the increasing number of people dying! It's really bad!".

Some participants associate the occurrence of COVID-19 with the end of human existence and the attribution of a certain luck for those who will survive. The participant vend precise that "it scares 
everyone... is it the end of the world? The unlucky ones will die and the lucky ones will survive!".

Fear is felt by participants who develop a feeling of negative affect and worry, especially in the facing of their daily and family lifestyle. In this sense, the participant ens1 says: "I read it on facebook, I read it on whatsapp, I received it from many other media and to me it was just like a joke! We were like "it is a white man's thing"! And the day it was announced that the first case was recorded in our country, I didn't know how to take it! I was somehow confused! I started thinking!... when we are fun of being together, moving together, playing together, holding ourselves and all, how is it going to be?".

In the same logic participant ens3 said that "to act on the world you must first survive...! So, the dead do not act on the world; so my real freedom is to first find the strategies to protect myself, to survive!".

Psychic repercussions of the experience due to the coronavirus threat

The actual experience of the coronavirus threat is not without consequences for the participants. Statistics on the inventory regarding the evolution of the pandemic at the global level in general and Cameroon in particular is more worrisome. Even if the figures announced by the Cameroonian ministry of health with regard to cases of remission or recovery appear to be appeasing compared to other countries like Italy, Spain, the United States or France, the fact remains that the rate of people infected per day continues to increase. Which increases fear, reinforces the feeling of insecurity, and a set of psychological reactions like stress, the development of conscious strategies or coping to protect oneself from the threat which is first real and which has psychic repercussions.

The participant's verbalisation trace a psychic discomfort felt "it makes us sensitive, it leads us to understand that we are very vulnerable!" (Participant Labo); "The epidemic shows us that, we are not all powerful! And then, this part of uncertainty itself! We don't know if tomorrow we will be alive! (Participant ens3).

"Truly there's fear because hearing something that you have not seen! We often say that, what is in a dark is more frightful especially something that you don't even know, you don't know how it is! You cannot recognize it by seeing it! So it's like you are fighting a ghost! So it is really frightful" (participant ens2).

Conscious strategies are therefore mobilized by participants who do not hesitate to implement barrier measures decreed by the government. Some participants are trying to find other strategies for dealing with the spread of the coronavirus. In this sense, the participant cond argue that "people are entering the car and that is how people are going down, so you don't know who you are carry- ing! [...] I'm not trusting anybody entering my car! When you enter my car the first thing I do is to educate you by saying that please put on your mask! Because, I'm afraid! I always use javel water to disinfect the car's door! So as to prevent coronavirus! I also wear my mask!”.

For the participant lead1, the confrontation with reality marked by the threat of the coronavirus, obliges him to develop a strategy linked to these religious and spiritual convictions. He says "I pray to the Lord so that this pandemic stops!" The participant retra recalls the barrier measures to be observed when she says "it's already confinement, protection with the mask when you go out! In short, respect hygiene measures, wash your hands regularly and therefore comply with all these conditions".

These strategies implemented by the participants lead them to formulate desires which, for the most of them, go in the direction of the wish to return to normal socio-economic and health activities in order to recover a certain homeostasis.

Real and subjective lived experiences linked to restrictive measures following COVID-19

The restrictive measures taken by the Cameroonian government are perceived by all the participants of the study (cond, lead1, ens1, ens2, ens3, retirement, vend, labo) as beneficial, but they nonetheless deplore some shortcomings and inadequacies that need to be filled. It is in this logic that the participant cond said that: "there are good measures because all is for the well-being of the citizen! But to a certain extend, the government has not put in place how the citizen will feel to relive their standard of leaving by taking these measures! For example, for my own job, they have said that we must limit the number of person that we are carrying in the vehicle! That is a good measure! But the government has not put in place to see if the taxi fare has changed or not! Or if possible, even drop the price of petrol! You see that in the market, prices of things have changed, of which automatically it does not need to change!".

In the same logic participant ens2 says "they say keep a meter distance, but in the taxi you can't keep a meter distance, because even you and the driver, you people are not a meter away. You and the next passenger you're not a meter away, so it's just risky everywhere. So even going out is limited, therefore I have no freedom of movement anymore".

The participant lead1 states that "it is difficult because as a pastor, our income is linked to the presence of members of the cult, we must give the tithing, we must give the offerings, and if today we have less than 50 people it's difficult!". The participant ens3 meanwhile, thinks that "the difficulty today is the difficulty of moving because transportation becomes expensive! Since the state has not taken any measures to stabilize the price, so you will pay almost double what we pay! “. For the participant ens1, hygienic measures 
are to be appreciated, but he deplores the fact that the current socio-economic context does not favor the application and the granting of certain products. He said "They talk of hand sanitizer, but they were no way to be found. For you to get it, it is difficult. When you see the price of the hand sanitizer, we use to buy for 1000 1500 Francs cfa. The prices were already at 2000- 2500frs! They talked of the face mask, even with the tissue is 500 Frs and it is not easy for people to get it! So to me, I was impress with the one of washing hands because they made things available for people to wash their hands!".

Psychological repercussions of the imposed social distancing

The participants of the study in their verbalisation, expressed the need to apply social distancing measures to limit the spread of the virus. However, the context in which these measures must be applied does not always favor its implementation. It is in this sense that some participants revealed the difficulty of applying it especially at the level of the microsystem, especially in family context. This leads to a climate of suspicion, a feeling of accusation linked and the sidelining of people who apply social distancing with member of their family. Social distancing therefore has consequences in terms of interactions and relationships between individuals. The anchoring is especially noticeable among families and those close to people. It is in this logic that the participant ens1 says "there are some negatives aspects! It has blocked me also from having a lot of things...I arrived somewhere and it is written on the gate "No visitors" and this is a house I used to go there. I am unable to reach, sit with my learners and then we learn together or with my colleagues and so on! [...] at the level of the family I can say I have failed because there is no way we can practise social distance with the family. We must sit together, we must pray together, we must interact together in the house or anywhere!".

In the same vein, the participant lead1 precise that: "Relationships are no longer the same because you cannot even approach family members any more, there is a certain mistrust towards family members. Even your wife, you cannot approach her anyhow, because you do not know if she carries virus and vice versa! It's really difficult! You cannot receive your father, your mother, your aunt who comes from the village, from the trip! There is a whole protocol to respect! Sometimes the family does not understand that it is necessary! Family members develop a worried look towards the person who respect these barrier measures!”.

The participants experienced frustration due to the imposition of social distancing, although some recognized its ability to limit the spread of the virus, others mentioned the difficulties in applying it. The participant vend says "for me it frustrates! It really frustrates, we are oblige to practise it! It gets complicated, it does not suit me! It is true that it hurts when someone comes towards you, and you take the distance, but we have to do it, because we do not know who is who! We must first avoid coronavirus!".

\section{Discussion}

The occurrence of COVID-19 has led to a health crisis and has had a considerable impact on the lives of people around the world in general [21] and in Cameroon in particular. The purpose of this study was to give a voice to people in the context of a health crisis, so that they can express their subjective lived experience with COVID-19. In other words, it was a question of understand the meaning that people give to their subjective lived experience in an anxious context marked by the health crisis due to the coronavirus.

Therefore, as already emphasized by Li and Zhu [9], it appears that the context of the lived experience of the coronavirus by people is marked by a strong anxiety felt by the populations in general and the participants of the study in particular. Because, starting from the experience lived before the occurrence of Covid-19, it appears that the participants managed to cope with the difficulties of daily life compared to the current context marked by COVID-19. The verbalizations first reveal a painful experience following the announcement of the occurrence of COVID-19. This is due to the sudden occurrence of COVID -19, which thus upsets lifestyle habits while imposing a reorganization of society in general and of people in particular [7]. It is in this context that the participant ens3 states that "I understood that there was something difficult that was going to happen! Something that was going to require new efforts or new adaptations compared to what was being done!".

The requirement for reorganization on a personal, community and societal level generally occurs in the event of a disaster, health crisis or any event threatening the survival of the individual [22]. This leads to upheavals which can harm the mental health of people as already demonstrated by Qiu., et al [5].

Thereby, participants emphasized a strong psychological reactions experienced through acute anxiety, painful emotions, fear, anger, feelings of weakness and insecurity, and stress. Faced with these painful experiences, the participants implemented a series of cognitive and behavioral efforts in order to manage the requirements imposed by the occurrence of COVID-19. Some participants mobilized problem-centered coping strategies like planning strategy as defined by Lazarus and Folkman [23], which consists in thinking about the steps to follow and how to manage the problem (participant cond), active coping consisting in minimizing the effect of the stressor, for example by increasing personal efforts (ens2, ens3), seeking for instrumental social support which consists in seeking information, advice and assistance (lead1, ens1). Emotioncentered coping was also identified in the participants' speech, such as emotional social support and the quest to understand the phenomenon.

Nevertheless, the restrictive measures imposed by the government are perceived positively despite the difficulty in being able to apply some of the measures due to the social, environmental and economic conditions of certain layers of the population, due to the 
level of precariousness observed and vulnerability. All these factors exacerbate the psychological fragility of people living in an anxious context marked by the coronavirus.

\section{Conclusion}

The change in lifestyle and behavior that has taken place in people following the occurrence of COVID-19 leads to an understanding of their subjective lived experience in the context of a health crisis. The qualitative study conducted with nine participants from different socio-professional layer, allows to understand what they are experiencing, feeling, their fear and their desire.

The phenomenological interpretative analysis allows to highlight, the experience of the participants marked by a strong felt anxiety, painful emotions, fear, anger, a feeling of weakness and insecurity, and stress. This forces them to implement cognitive and behavioral efforts (planning strategy, active coping, seeking instrumental social support and emotion-centered coping) aimed at protecting themselves from the anxiety they feel.

The same phenomena of psychological distress, especially anxiety and fear were prevalent among patient with COVID-19 as reported Xu., et al. [24] and also on people facing a situation of total confinement in the context of COVID-19 in China as suggested by Qiu., et al [5]. However, faced with COVID-19, people in Cameroon do not experience a situation of total confinement, but rather a restriction in the functioning of certain activities $[14,15]$. This means that the anxious context marked by COVID-19 leads to these experiences because it creates confrontation with uncertainty, insecurity, and to the unknown or even imminent death.

Therefore, the need for psychological care turns out to be a necessity in the context of a health crisis. This need for psychological support was highlight by the participants who, in addition to these painful experiences, have to face the many upheavals in their daily activities; and they must also observe the requirement for social distancing. In this sense, social distancing is perceived by the participants as a measure aimed at reinforcing the feeling of distancing, distrust and breakdown of the family unit as thought by Thompson and Rasmussen [25].

It is important to consider another study that could assess the impact of social distancing on families in the context of a health crisis and on a larger scale. Also, by varying the data collection tools and increasing the sample size of the study, one could analyse the subjective experience of people in a disaster context.

\section{Conflict of Interest}

No conflict of interest.

\section{Bibliography}

1. INSERM. "Coronavirus et Covid-19: Du simple rhume au syndrome respiratoire aigu sévère”. Repéré sur inserm.fr (2020).

2. WHO. "Syndrome respiratoire aigu sévère (SRAS): Statut de la flambée et leçons pour l'avenir". Faire tomber les masques". Genève (2003).

3. Wordometer. Repéré sur (2020).

4. Trackcorona. Repéré du site (2020).

5. Qiu J Shen B., et al. "A nationwide survey of psychological distress among Chinese people in the COVID-19 epidemic implications and policy recommendations". General Psychiatry 33.2 (2020).

6. Xiang Y-T, Yang Y, Li W et al. "Timely mental health care for the 2019 novel coronavirus outbreak is urgently needed". Lancet Psychiatry (2020).

7. Wang W., et al. "Updated understanding of the outbreak of 2019 novel coronavirus (2019-nCoc) in Wuhan, China”. Journal of Medical Virology 92.4 (2020): 441-447.

8. Liu S., et al. "Online mental health services in China during the COVID-19 outbreak". Lancet Psychiatry 7 (2020): 17-18.

9. Li D and Zhu G. "Psychological interventions for people affected by the COVID-19 epidemic". Lancet Psychiatry (2020).

10. Brooks S-K., et al. "The psychological impact of quarantine and how to reduce it". Rapid Review of the Evidence 395 (2020): 912-920.

11. TV5 monde infos. "Coronavirus en Afrique : quelles conséquences économiques?" repéré du site (2020).

12. Jeune Afrique économique. "Coronavirus : les dernières infos économiques africaines". Repéré du site (2020).

13. Lai J., et al. "Factors associated with mental health outcomes among health care workers exposed to coronavirus Disease 2019". JAMA Network Open 3.3 (2020).

14. Prime Minister Office. "Communiqué portant Mesures de restriction prises par le Chef de l'Etat le 17 mars 2020". Repéré du site (2020).

15. Prime Minister Office. "Stratégie gouvernementale de riposte face à la pandémie de coronavirus (covid-19), déclaration spéciale du premier ministre, chef du gouvernement du 24 mars 2020" Repéré du site (2020). 
16. Smith J., et al. "Interpretative phenomenological analysis: Theory, method and research". London: Sage Publications Ltd (2009).

17. Fernandez L and Catteeuw M. "La recherche en psychologie clinique”. Paris: Nathan (2001).

18. Douville 0. "Les méthodes cliniques en psychologie". Paris: Dunod (2006).

19. Muchielli A. "Dictionnaire des méthodes qualitatives en sciences humaines et sociales".3è édition. Paris: Armand Colin (2009).

20. Antoine $\mathrm{P}$ and Smith J. "Saisir l'expérience: présentation de l'analyse phénoménologique interprétative comme méthodologie qualitative en psychologie". Psychologie Française (2016): 1-13.

21. WHO. "Flambée de la maladie à coronavirus 2019 (COVID-19)".Repéré du site (2020).

22. Roberts AR. "Crisis intervention handbook: assessment, treatment, and research". $3^{\text {rd }}$ edition Oxford University press (2005).

23. Lazarus, R., Folkman, S. "Stress, appraisal, and coping". New York: Springer (1984).

24. Xu K., et al. "Management of coronavirus disease-19 (COVID-19): The Zhejiang experience". Pub Medicine 49.1 (2020).

25. Thompson L and Rasmussen SA. "What does the coronavirus Disease 2019 (COVID-19) mean for Families?" The Journal of the American Medical Association (2020).

\section{Assets from publication with us}

- Prompt Acknowledgement after receiving the article

- Thorough Double blinded peer review

- Rapid Publication

- Issue of Publication Certificate

- High visibility of your Published work

Website: www.actascientific.com/

Submit Article: www.actascientific.com/submission.php

Email us: editor@actascientific.com

Contact us: +919182824667 